\title{
TRANSMISSION SYSTEM POWER FLOW MODEL
}

Physical modelling of transportation system is helpful for finding information about the power flow in particular transmission elements. The vehicle power train model can be built from predefined blocks. The blocks are based on mathematical equations, which define every power train element. The procedure of the particular transmission element - a two-stage epicyclic gearbox model creation and calculation is described in the presented article.

Keywords: Gear system, power flow, model, simulation.

\section{Introduction}

The mathematical model of a gear system presented in this article is based on the principle of physical modelling of individual blocks representing elements of modelled transmission structure [1].

If the base data of the gearbox are known, the model of the gearbox inner structure can be built. The most important parameters for the calculation of epicyclic gear trains are fundamental ratios of the gearbox stages $u_{\mathrm{v} 1}$ and $u_{\mathrm{v} 2}$ and input performance parameters. The fundamental gear ratios define the internal structure of the gearbox. They are determined by the number of gear teeth in each stage of the gearbox. The performance parameters, after conversion from relative magnitudes obtained by simulation, determine the load on each element of the gearbox [2 and 3].

\section{Gear train description}

The calculated gear train (Fig. 1) is formed by two simply planetary gear stages, which are linked in series. The 1-st stage sun gear $p_{1}$ is connected to the input shaft $A$ and the 2-nd stage carrier $r_{2}$ is connected to the output shaft $X$. The 1-stage carrier $r_{1}$ is connected to the 2-nd stage sun gear $p_{2}$. Ring gears $q_{1}$ and $q_{2}$ in both gear stages are fixed to the gearbox case.

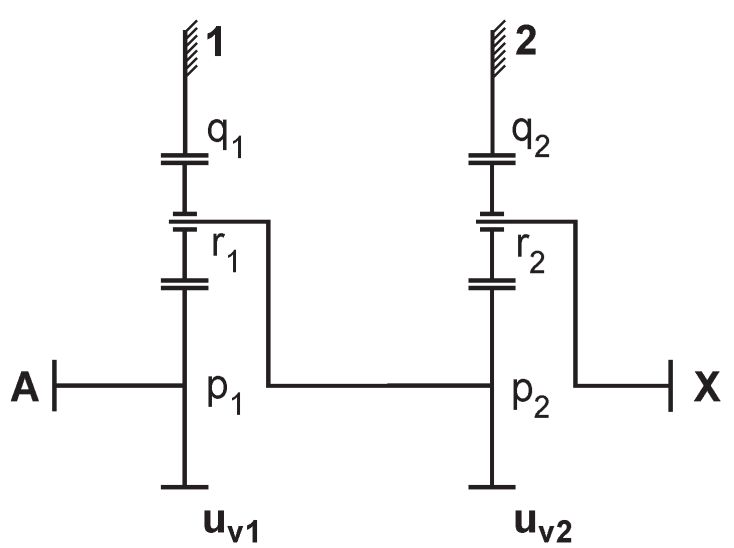

Fig. 1 Scheme of the solved two-stage epicyclic gear train

(Source: authors)

\section{Gear stage kinematics}

The basic elements of the model are blocks of one-stage planetary gearbox defined by Mathworks Simcape Driveline software. The basic equation, which characterises the epicyclic gear train with 3 basic elements (sun gear $p$, ring gear $q$ and carrier $r$-Fig. 2) and 2 degrees of freedom (DOF), is so called Willis formula [4]:

$\omega_{p}-\omega_{q} u_{v}=\omega_{r}\left(1-u_{v}\right)$

where: $\omega_{\mathrm{p}}$ speed of the central wheel $p$ (sun gear),

\footnotetext{
* ${ }^{1}$ Michal Lukac, ${ }^{1}$ Frantisek Brumercik, ${ }^{2}$ Leszek Krzywonos, ${ }^{3}$ Zbigniew Krzysiak ${ }^{1}$ Mechanical Engineering Faculty, University of Zilina, Slovakia

${ }^{2}$ Lublin University of Technology, Faculty of Mechanical Engineering, Poland

${ }^{3}$ University of Life Science in Lublin, Faculty of Production Engineering, Poland

E-mail: brumercikf@fstroj.uniza.sk
} 
$\omega_{1} \quad$ speed of the central wheel $q$ (ring gear),

$\omega_{r} \quad$ speed of the carrier $r$,

uv fundamental epicyclic gear ratio.

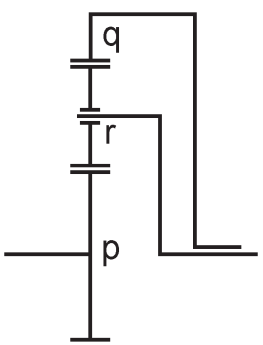

Fig. 2 Single epicyclic gear train with internal geared ring gear:p - sun gear, $r$ - carrier, $q$ - ring gear (Source: authors)

The fundamental epicyclic gear ratio is defined by the stopped carrier $r$ as

$u_{v}= \pm \frac{z_{q}}{z_{p}}=\frac{\omega_{p}}{\omega_{q}} \mid \omega_{r}=0$,

where: $z_{\mathrm{q}}$ tooth number of the central wheel $\mathrm{q}$, zp tooth number of the central wheel $p$.

The sense of the gear ratio is negative, if the central wheel $q$ has internal gearing, which is the case of both of the twolinked simple epicyclic gear trains solved in this task.

\section{Model environment and blocks}

Matlab/SimScape is the computing environment equipped with blocks not only for mechanical, but also for the electrical, electromagnetic, hydraulic and pneumatic, fluid, and thermal models. It includes blocks, which are generally used by solving of any type of the upper described models and can be taken as a common base of blocks that are also useful with the connection with Driveline blocks, which describe common elements often used by the drivetrain modelling [5].

Following the principles of physical model building, it is necessary to connect block ports with input and output shafts of the gearbox, to connect the ports defining the inner structure of the gearbox and to fix the necessary element of the gearbox to obtain the DOF number equal to 1 . The blocks, which are required for building a mathematical model for the power flow analysis of the calculated gear train, are described below.

\subsection{Planetary gear block}

Figure 3 shows the mask of the planetary gear block in Matlab/SimScape Driveline software.

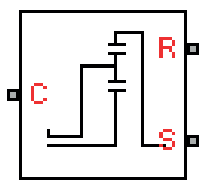

Fig. 3 Planetary gear block (Source: [5])

The planetary gear block has three connection ports:

- C - Carrier,

- S - Sun gear,

- R - Ring gear.

This block allows to define the fundamental gear ratio of the planetary gear-stage, e.g. by the number of gear teeth of the sun gear $p$ and ring gear $q$ put to the block parameters interface. Torque and angular velocity can be calculated by this block either with or without losses in gear mesh with the possibility to take into account the impact of the temperature and also the viscous losses from bearing of the sun and planet gears.

\subsection{Rotational reference block}

The calculated gearbox is formed by two simple planetary gear stages, which are linked in series. Ring gears in both gear stages are fixed to the gearbox case. Modelling of this structural condition requires the usage of the general Matlab/ Simscape block library.

This task requires the mechanical rotational reference block (Fig. 4). This block ensures the zero speed of connected ports during the calculation.

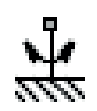

Fig. 4 Mechanical rotational reference block (Source: [5])

\subsection{Ideal torque source block}

The calculation of speeds and torques of planetary mechanism elements formed by two stages requires to enter the initial values at the start of the simulation. Presented mathematical model has the input initial condition defined 
by the relative input torque $M_{\mathrm{A}}=1$, which is applied on the gearbox input shaft A by the ideal torque source block (Fig. 5).

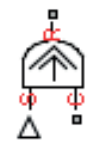

Fig. 5 Ideal torque source block (Source: [5])

The ideal torque source block has 3 ports:

- R - Mechanical rotational conserving port.

- C - Mechanical rotational conserving port associated with the source reference point (case).

- S - Physical signal input port, through which the control signal that drives the source is applied.

The block positive direction is from port $\mathrm{C}$ to port $\mathrm{R}$. This means that the torque is positive if it acts in the direction from $\mathrm{C}$ to $\mathrm{R}$. The power generated by the source is negative if the source delivers energy to port $\mathrm{R}$.

4.4 Ideal angular velocity source block

Presented mathematical model has the output initial condition defined by the relative output speed $\mathrm{w}_{\mathrm{A}}=1$, which is applied on the gearbox output shaft $\mathrm{X}$ by the ideal angular velocity source block (Fig. 6).

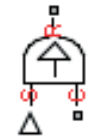

Fig. 6 Ideal angular velocity source block (Source: [5])

This block has 3 connectors:

- R - Mechanical rotational conserving port,

- C - Mechanical rotational conserving port associated with the source reference point (case),

- S - Physical signal input port, through which the control signal that drives the source is applied.

Positive value of torque is defined by its action from connector $\mathrm{R}$ to the connector $\mathrm{C}$. Relative angular velocity is defined by this block as

$\omega=\omega_{R}-\omega_{c}$

In the built-up model, the input relative angular velocity is defined as $\mathrm{w}_{\mathrm{A}}=1$. If the gear ratio is known, the value of the relative angular output velocity is calculated as

$\omega_{X}=\frac{\omega_{A}}{i_{A X}}=\frac{1}{i_{A X}}$
The angular velocity and torque of individual mechanism model elements are detected with sensor blocks.

\subsection{Ideal torque sensor block}

The Ideal Torque Sensor block represents a device that converts a variable passing through the sensor into a control signal proportional to the torque. The sensor is ideal because it does not account for inertia, friction, delays, energy consumption, and so on. The Ideal torque sensor block mask is shown in Fig. 7

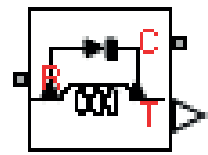

Fig. 7 The block-Ideal Torque Sensor (Source: [5])

This block has 3 connectors:

- $\mathrm{R}$ - Mechanical rotational conserving port associated with the sensor positive probe.

- C-Mechanical rotational conserving port associated with the sensor negative (reference) probe.

- T- Physical signal output port for torque.

\subsection{Ideal rotation motion sensor block}

The Ideal Rotational Motion Sensor block represents an ideal mechanical rotational motion sensor, that is a device converting an across variable measured between two mechanical rotational nodes into a control signal proportional to angular velocity or angle. The sensor is ideal since it does not account for inertia, friction, delays, energy consumption, and so on.

The Ideal torque sensor block mask is shown in Fig. 8.

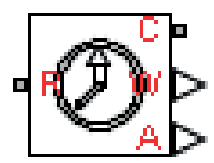

Fig. 8 The block Ideal Rotational Motion Sensor (Source: [5])

This block has 4 connectors:

- $\mathrm{R}$ - Mechanical rotational conserving port associated with the sensor positive probe,

- C - Mechanical rotational conserving port associated with the sensor negative (reference) probe, 
- W - Physical signal output port for angular velocity,

- A - Physical signal output port for angular displacement.

\section{Model calculation}

After finishing the system model, there is need to define the block solver configuration, which performs the calculation [6 and 7]. It is also necessary to define the parameters of the numerical calculation method used for the model, which are suitable for the solution of a particular calculation problem.

The method used for the calculation of the presented gear train was the Runge-Kutta method (ode4 solver) with the fixed time step of $0.001 \mathrm{~s}$.

For the solution of the presented gear train was made a complex model consisting of two blocks of simple planetary gear (series connected) with the ideal torque source at the input and the ideal angular velocity source at the output. The block connectors are connected with lines representing rigid immaterial shafts, which generates the possibility to do also the static analysis of relative torques, angular velocities and performances of individual elements of the mechanism [8]. Performance parameters of the power flow are monitored with custom developed power sensors. The results are interpreted in the form of numerical values of the various parameters displayed on scopes connected to every tested element of the gearbox [9].

The complex gearbox model without calculating mesh losses in gears with the relative torques, angular velocities and performances parameters is shown in Fig. 9.

The complex gearbox model with calculating mesh losses in gears with the relative torques, angular velocities and

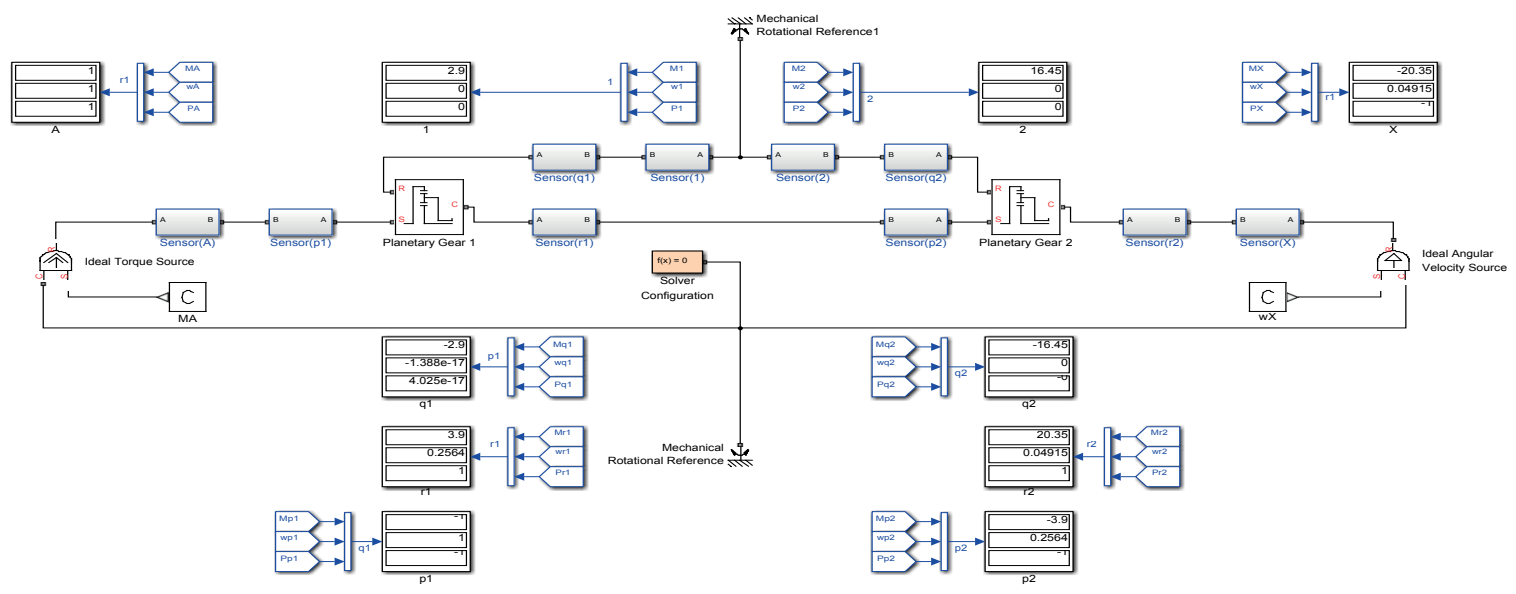

Fig. 9 Gearbox model - calculation without gear mesh losses (Source: authors)

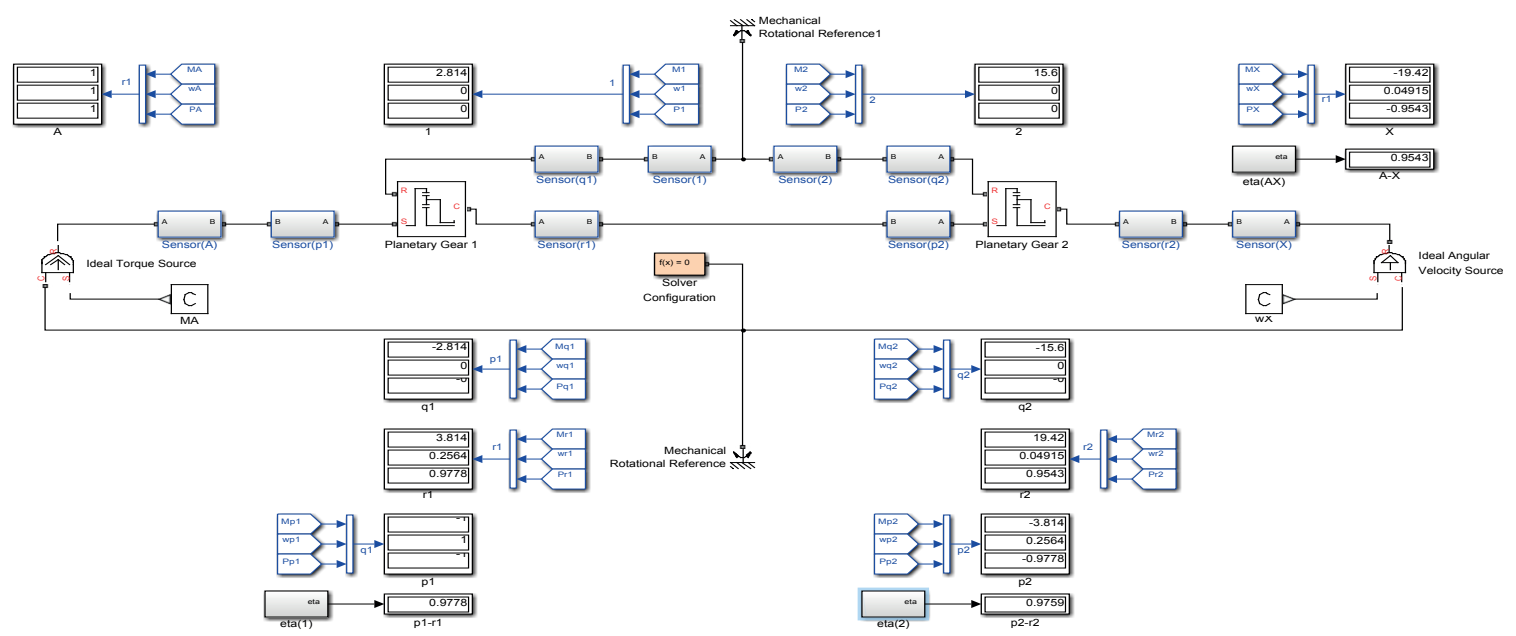

Fig. 10 Gearbox model - calculation with gear mesh losses (Source: authors) 
performances parameters is shown in Fig. 10. The effectiveness of the external gear mesh was defined as $\eta_{e}=0.98$ and the effectiveness of the internal gear mesh as $\eta_{i}=0.99$ [10].

\section{Conclusion}

The article presents simulation results of an unconventional vehicle transmission, which can be used in commercial vehicles and mobile working machines. The kinematic structure and the dynamic behaviour of the system are extracted into the mathematical model [11]. Thus, the simulation of number of load cases can be done and the control system can be tested without the need of number of prototypes to be built. The model provides also the possibility of the powertrain efficiency calculation. This allows to shorten the development time and to cut the costs in the area of R \& D process significantly [12].

\section{Acknowledgement}

This paper presents results of work supported by the Slovak Scientific Grant Agency of the Slovak Republic under the project No. VEGA 1/0077/15.

\section{References}

[1] DROZDZIEL, P., KRZYWONOS, L.: The Estimation of the Reliability of the First Daily Diesel Engine Start-up During its Operation in the Vehicle. Eksploatacja i Niezawodnosc - Maintenance and Reliability, 1(41), 2009, 4-10.

[2] GLOWACZ, A.: Diagnostics of DC and Induction Motors Based on the Analysis of Acoustic Signals. Measurement Science Review, vol. 14, No. 5, 2014, 257-262.

[3] KOHAR, R., HRCEK, S.: Dynamic Analysis of a Rolling Bearing Cage with Respect to the Elastic Properties of the Cage for the Axial and Radial Load Cases. Communications - Scientific Letters of the University of Zilina, vol. 16, No. 3A, 2014, 74-81.

[4] HRCEK, S., KOHAR, R., MEDVECKY, S.: Determination on the Maximum Roller Bearing Load with Regards to Durability thereof using FEM Analysis. Communications - Scientific Letters of the University of Zilina, vol. 14, No. 3, 2012, 55-61.

[5] DROZDZIEL, P., KOMSTA, H., KRZYWONOS, L.: Repair Costs and the Intensity of Vehicle Use. Transport Problems, vol. 8, No. 3, 2013, 131-138.

[6] KOHAR, R., HRCEK, S., MEDVECKY, S.: Usage of Dynamic Analysis to Determine Force Interactions between Components of Rolling Bearings. Communications - Scientific Letters of the University of Zilina, vol. 14, No. 3, 2012, 62-67.

[7] KOMSTA, H., BRUMERCIKOVA, E., BUKOVA, B.: Applications of NFC Technology in Passenger Rail Transport. Transport Problems, vol. 11, No. 3, 2016, 43-53.

[8] CABAN, J., DROZDZIEL, P., BARTA, D., LISCAK, S.: Vehicle Tire Pressure Monitoring Systems, Diagnostyka, vol. 15, No. 3, 2014, ISSN 1641-6414.

[9] Matlab reference, 1994-2016 The MathWorks, Inc.

[10] CABAN J., MARCZUK A., SARKAN B., VRABEL J.: Studies on Operational Wear of Glycol-Based Brake Fluid. Przemyst Chemiczny, vol. 94, No. 10, 2015, 1802-1806.

[11] BRUMERCIKOVA, E., BUKOVA, B., KRZYWONOS, L.: NFC Technology in Public Transport. Communications - Scientific Letters of the University of Zilina, vol. 18, No. 2, 2016, 20-25.

[12] BUKOVA, B., BRUMERCIKOVA, E., KONDEK, P., SOJCAK, D.: The Impact of International Intrepreneurship on the Development of Transport. Communications - Scientific Letters of the University of Zilina,, vol. 18, No. 2, 2016, $139-142$. 